\title{
EFEKTIVITAS PERAWATAN PAYUDARA DAN PIJAT OKSITOSIN TERHADAP PENGELUARAN ASI DI PUSKESMAS PUTRI AYU KOTA JAMBI TAHUN 2019
}

\author{
Diniyati, Lidwina Trieleventa Lumruan Sihombing, Enny Susilawati \\ Jurusan Kebidanan Poltekkes Jambi
}

\begin{abstract}
Abstrak
Masalah menyusui pada umumnya terjadi dalam dua minggu pertama masa nifas. Pada masa ini, pengawasan dan perhatian petugas kesehatan sangat diperlukan agar masalah menyusui dapat segera ditanggulangi, sehingga tidak menjadi penyulit atau menyebabkan kegagalan menyusui.Dampak yang ditimbulkan payudara bengkak, saluran susu tersumbat, mastitis dan abses payudara.Data dari Dinas Kesehatan Kota Jambi tahun 2017 jumlah ibu postpartum di Puskesmas Putri Ayu sebanyak 1.232 orang. Penelitian ini merupakan penelitian analitik dengan menggunakan quasi eksperimentbertujuan untuk mengetahui efektivitas perawatan payudara dan pijat oksitosin terhadap pengeluaran ASI pada ibu post partum di Puskesmas Putri Ayu Kota Jambi Tahun 2019.Penelitian ini dilakukan pada bulanDesember-Juli 2019.Jumlah sampel yang diteliti berjumlah 60 orang.Pada penelitian ini cara pengambilan sampel dengan menggunakan teknik accidental sampling. Tehnik pengumpulan data menggunakan lembar observasi. Hasil penelitian dianalisis secara univariat dan bivariat. Hasil analisis didapatkan pengeluaran ASI yang lancar setelah perawatan payudara sebanyak 33,33\% dan tidak lancar 66,67\%. Pengeluaran ASI yang lancar setelah pijat oksitosin sebanyak $83,33 \%$ dan tidak lancar $16,67 \%$. Efektivitas perawatan payudara dan pijat oksitosin diperoleh nilai $p$ value $=0,000(p<0,005)$. Mean perawatan payudara sebesar 23,00 dan mean pijat oksitosin sebesar 38,00 yang berarti pijat oksitosin lebih efektif daripada perawatan payudara. Bagi Puskesmas Putri Ayu untuk dapat meningkatkan kualitas dan kuantitas para ibu post partum dalam melakukan perawatan payudara dan pijat oksitosin.Bagi Poltekkes Kemenkes Jambi dapat dijadikan sebagai bahan bacaan. Bagi peneliti lain dapat melakukan penelitian tentang masalah yang sama pada tempat dan variabel yang berbeda.
\end{abstract}

Kata kunci : Perawtan payudara, pijat oksitosin, pengeluaran ASI

\section{PENDAHULUAN}

Masa nifas atau masa puerperium adalah masa setelah partus selesai, dan berakhir setelah kira-kira 6 minggu. Istilah puerperium (berasal dari kata puer artinya anak, parele artinya melahirkan) menunjukkan periode 6 minggu yang berlangsung antara berakhirnya periode persalinan dan kembalinya organ-organ reproduksi wanita ke kondisi normal seperti sebelum hamil (Mayurnarni, 2009: 5).

Menurut data hasil Ditjen Kesehatan Masyarakat tahun 2017 jumlah ibu postpartum di Indonesia sebanyak 5.078.636 orang. Berdasarkan data Profil Kesehatan Indonesia tahun 2017 jumlah ibu postpartum di Provinsi Jambi sebanyak 69.774 orang dan jumlah ibu post partum di kota Jambi sebanyak 13.078 orang (Dinas Kesehatan Kota Jambi tahun 2017).

Masalah menyusui pada umumnya terjadi dalam dua minggu pertama masa nifas. Pada masa ini, pengawasan dan perhatian petugas kesehatan sangat diperlukan agar masalah menyusui dapat segera ditanggulangi, sehingga tidak menjadi penyulit atau menyebabkan kegagalan menyusui. Masalah yang biasanya terjadi dalam pemberian ASI adalah puting susu lecet, payudara bengkak, saluran susu tersumbat, mastitis dan abses payudara. Oleh karena itu, untuk menghindari agar kondisi semacam ini tidak terjadi maka diperlukan perawatan payudara (Saleha, 2013: 102-110).

Perawatan payudara merupakan suatu tindakan perawatan payudara yang dilaksanakan, baik oleh pasien maupun dibantu oleh orang lain yang dilaksanakan mulai hari pertama atau kedua setelah melahirkan. Perawatan payudara bertujuan untuk memperlancar sirkulasi darah dan mencegah tersumbatnya saluran susu sehingga memperlancar pengeluaran ASI, menjaga agar payudara senantiasa bersih dan terawat (puting susu) karena saat menyusui payudara ibu akan kontak langsung dengan mulut bayi, menghindari puting susu yang sakit dan infeksi payudara dan menjaga keindahan bentuk payudara (Yetti, 2010).

Payudara menghasilkan ASI dimulai ketika seorang bayi mulai menyusu pada puting seorang wanita, yakni hasil perangsangan fisik menyebabkan impuls. Impuls pada ujung saraf dikirim ke kelenjar hipotalamus di otak yang secara bergantian memberitahu kelenjar pituitari yang juga berada di otak 
untuk menghasilkan dua hormon yang disebut oksitosin dan prolaktin. Prolaktin menyebabkan susu diproduksi dan oksitosin menyebabkan serat otot yang mengelilingi kelenjar alveoli mengerut seperti pada otot rahim. Saat serat otot di sekeliling kelenjar alveoli berkerut, maka menyebabkan susu menjadi keluar yang disebut sebagai aliran sehingga dapat menimbulkan sensasi dalam payudara lalu menyemprotkan susu dari putingnya. Semakin bayi menghisap, semakin banyak susu yang dihasilkan (Yuli, 2014: 53).

Selain perawatan payudara, pijat stimulasi oksitosin untuk ibu menyusui juga berfungsi untuk merangsang hormon oksitosin agar dapat memperlancar ASI dan meningkatan kenyamanan ibu. Pijat oksitosin juga dapat didefinisikan sebagai tindakan yang dilakukan oleh keluarga, terutama suami pada ibu menyusui yang berupa pijatan pada punggung ibu untuk meningkatkan produksi hormone oksitosin. Sehingga dapat mempercepat penyembuhan luka bekas implantasi plasenta, mencegah perdarahan, serta memperbanyak produksi ASI. Pijat stimulasi oksitosin untuk ibu menyusui berfungsi untuk merangsang hormon oksitosin agar dapat memperlancar ASI dan meningkatan kenyamanan ibu (Suherni, 2008).

Menurut penelitian Inneke (2014), Pijat Oksitosin lebih efektif dibandingkan perawatan payudara dan menurut Hotmaria (2015), Pijat Oksitosin lebih efektif dibandingkan perawatan payudara.

\section{METODE DAN CARA KERJA}

Penelitian ini merupakan penelitian analitik. Rancangan penelitian ini yaitu quasi eksperiment dengan menggunakan two group pretest-posttest design yaitu dengan cara observasi dilakukan dua kali yaitu sebelum eksperimen (O1) disebut pretest, dan sesudah eksperimen (O2) disebut dengan posttest.

\section{HASIL DAN PEMBHASAN}

1. Gambaran produksi ASI pada ibu post partum sebelum dilakukan perawatan payudara di Puskesmas Putri Ayu Kota Jambi tahun 2019

Tabel 5.1

Distribusi Produksi ASI pada Ibu Post Partum sebelum Dilakukan Perawatan Payudara di Puskesmas Putri Ayu Kota Jambi Tahun 2019 $\mathbf{f}=\mathbf{3 0}$

\begin{tabular}{clcc}
\hline \multirow{2}{*}{ No } & Produksi ASI setelah & \multicolumn{2}{c}{ Distribusi } \\
\cline { 3 - 4 } & Perawatan Payudara & $\mathrm{f}$ & $\%$ \\
\hline 1 & Lancar & 7 & 23,3 \\
\hline 2 & Tidak Lancar & 23 & 76,7 \\
\hline & Total & 30 & 100 \\
\hline
\end{tabular}

Berdasarkan hasil analisis deskriptif untuk produksi ASI sebelum dilakukan perawatan payudara di Puskesmas Putri Ayu Kota Jambi Tahun 2019 didapatkan sebanyak $23(76,7 \%)$ responden produksi ASI tidak lancar.
2. Gambaran produksi ASI pada ibu post partum setelah dilakukan perawatan payudara di Puskesmas Putri Ayu Kota Jambi Tahun 2019

Tabel 5.2

Distribusi Produksi ASI pada Ibu Post Partum setelah Dilakukan Perawatan Payudara di Puskesmas Putri Ayu Kota Jambi Tahun 2019 $\mathbf{f}=\mathbf{3 0}$

\begin{tabular}{clcc}
\multirow{2}{*}{ No } & Produksi ASI setelah & \multicolumn{2}{c}{ Distribusi } \\
\cline { 3 - 4 } & Perawatan Payudara & $\mathrm{f}$ & $\%$ \\
\hline 1 & Lancar & 10 & 33,33 \\
\hline 2 & Tidak Lancar & 20 & 66,67 \\
\hline & Total & 30 & 100 \\
\hline
\end{tabular}

Berdasarkan hasil analisis deskriptif untuk produksi ASI pada ibu post partum yang dilakukan perawatan payudara didapatkan sebanyak $20(66,67 \%)$ responden produksi ASI tidak lancar.

3. Gambaran produksi ASI pada ibu post partum sebelum dilakukan pijat oksitosin di Puskesmas Putri Ayu Kota Jambi tahun 2019

\section{Tabel 5.3}

Distribusi Produksi ASI pada Ibu Post Partum sebelum Dilakukan Pijat Oksitosin di Puskesmas Putri Ayu Kota Jambi Tahun 2019 $\mathbf{f}=\mathbf{3 0}$

\begin{tabular}{llcc}
\hline No & $\begin{array}{c}\text { Produksi ASI setelah } \\
\text { Pijat Oksitosin }\end{array}$ & \multicolumn{2}{c}{ Distribusi } \\
\cline { 3 - 4 } & & $\mathrm{f}$ & $\%$ \\
\hline 1 & Lancar & 11 & 36,7 \\
\hline 2 & Tidak Lancar & 19 & 63,3 \\
\hline & Total & 30 & 100 \\
\hline
\end{tabular}

Berdasarkan hasil analisis deskriptif untuk produksi ASI pada ibu post partum sebelum dilakukan pijat oksitosin di Puskesmas Putri Ayu Kota Jambi tahun 2019 sebanyak 11 (36,7\%) responden produksi ASI lancar.

4. Gambaran produksi ASI pada ibu post partum setelah dilakukan pijat oksitosin pada ibu post partum di Puskesmas Putri Ayu Kota Jambi Tahun 2019

Tabel 5.4

Distribusi Produksi ASI pada Ibu Post Partum setelah Dilakukan Pijat Oksitosin di Puskesmas Putri Ayu Kota Jambi Tahun 2019 $\mathbf{f}=\mathbf{3 0}$

\begin{tabular}{llcc}
\hline No & $\begin{array}{c}\text { Produksi ASI setelah } \\
\text { Pijat Oksitosin }\end{array}$ & \multicolumn{2}{c}{ Distribusi } \\
\cline { 3 - 4 } & \multicolumn{1}{c}{ f } & $\%$ \\
\hline 1 & Lancar & 25 & 83,33 \\
\hline 2 & Tidak Lancar & 5 & 16,67 \\
\hline & Total & 30 & 100 \\
\hline
\end{tabular}

Berdasarkan hasil analisis deskriptif untuk produksi ASI pada ibu post partum setelah dilakukan pijat oksitosin di Puskesmas Putri Ayu Kota Jambi 
tahun 2019 sebanyak $25(83,33 \%)$ responden produksi ASI lancar.

Manfaat pijat oksitosin adalah merangsang reflek let down, memberikan kenyamanan pada ibu, mengurangi bengkak (engorgement), mengurangi sumbatan ASI, merangsang hormon oksitosin, mempertahankan produksi ASI ketika ibu dan bayi sakit. Pijatan pada tulang belakang neurotransmitter akan merangsang medulla oblongata langsung mengirim pesan ke hypothalamus di hypofise posterior untuk mengeluarkan oksitosin sehingga menyebabkan buah dada mengeluarkan air susunya. Pijat oksitosin bisa dilakukan kapanpun ibu mau dengan durasi 3-5 menit, lebih disarankan dilakukan sebelum menyusui atau memerah ASI sehingga untuk mendapatkan jumlah ASI yang optimal dan baik, sebaiknya pijat oksitosin dilakukan setiap hari dengan durasi 3-5 menit.

5. Efektivitas Perawatan Payudara dan Pijat Oksitosin Post Partum terhadap produksi ASI di Puskesmas Putri Ayu Kota Jambi Tahun 2019

Tabel 5.5

Efektivitas perawatan payudara dan pijat oksitosin terhadap produksi ASI post partum di Puskesmas Putri Ayu Kota Jambi Tahun 2019

\begin{tabular}{cccccc}
\multicolumn{6}{c}{$\mathbf{n = 6 0}$} \\
\hline No & $\begin{array}{c}\text { Produksi } \\
\text { ASI }\end{array}$ & $\begin{array}{c}\text { Mean } \\
\text { Sebelum }\end{array}$ & $\begin{array}{c}\text { Mean } \\
\text { Sesudah }\end{array}$ & $\begin{array}{c}\text { Sum } \\
\text { Of } \\
\text { Ranks }\end{array}$ & $\begin{array}{c}\text { Sig. } \\
(2- \\
\text { tailed }\end{array}$ \\
\hline 1 & $\begin{array}{l}\text { Perawatan } \\
\text { Payudara }\end{array}$ & 0,23 & 0,33 & 6,00 & 0,083 \\
\hline 2 & $\begin{array}{l}\text { Pijat } \\
\text { Oksitosin }\end{array}$ & 0,37 & 0,83 & 105,00 & 0,000 \\
\hline
\end{tabular}

Wilcoxon Test

Berdasarkan hasil penelitian didapatkan pijat oksitosin lebih efektif dengan bertambahnya nilai mean sebesar $(0,46)$ dalam produksi ASI dibandingkan dengan perawatan payudara dengan bertambahnya nilai mean sebesar $(0,10)$. Dari Hasil uji statistik Wilcoxon Test diperoleh nilai $p$-value sebelum-sesudah perawatan payudara 0,083 dan $p$-value sebelum-sesudah pijat oksitosin $0,000 \quad(\mathrm{p}<0,005)$ berarti pijat oksitosin lebih efektif dari perawatan payudara.

Pijat Oksitosin akan membuat rileks dan menghilangkan stress, sehingga mempercepat neurotransmitter merangsang medulla oblongata untuk mengirim pesan ke hypothalamus di hypofise posterior kemudian dihasilkan oksitosin sehingga ASI keluar. Teknik lain yang dapat mempengaruhi pengeluaran ASI adalah perawatan payudara yang bertujuan untuk melancarkan sirkulasi darah dan mencegah tersumbatnya saluran produksi ASI, sehingga memperlancar pengeluaran ASI.

\section{KESIMPULAN}

Berdasarkan hasil penelitian dan analisis tentang efektivitas perawatan payudara dan pijat oksitosin terhadap pengeluaran ASI di Puskesmas Putri Ayu Kota Jambi Tahun 2019, maka dapat ditarik kesimpulan sebagai berikut: Sebagian besar $(76,7 \%)$ responden mengalami pengeluaran ASI tidak lancar dan sebagian kecil $(23,3 \%)$ responden pengeluaran ASI lancar sebelum dilakukan perawatan payudara. Sebagian besar $(66,67 \%)$ responden mengalami pengeluaran ASI tidak lancar dan sebagian kecil $(33,33 \%)$ responden pengeluaran ASI lancar setelah dilakukan perawatan payudara. Sebagian besar $(63,3 \%)$ responden mengalami pengeluaran tidak lancar dan sebagian kecil $(36,7 \%)$ responden mengalami pengeluaran ASI lancar sebelum dilakukan pijat oksitosin. Sebagian besar $(83,33 \%)$ responden mengalami pengeluaran ASI lancar dan sebagian kecil $(16,67 \%)$ responden pengeluaran ASI tidak lancar setelah dilakukan pijat oksitosin. Pijat Oksitosin lebih efektif daripada perawatan payudara terhadap pengeluaran ASI dengan nilai $p$ value 0,000 $(\mathrm{p}<0,005)$. 